\title{
Research
}

\section{Factors affecting the decision to investigate older adults with potential cancer symptoms:}

\author{
a systematic review
}

\begin{abstract}
Background

Older age and frailty increase the risk of morbidity and mortality from cancer surgery and intolerance of chemotherapy and radiotherapy. The effect of old age on diagnostic intervals is unknown; however, older adults need a balanced approach to the diagnosis and management of cancer symptoms, considering the benefits of early diagnosis, patient preferences, and the likely prognosis of a cancer.
\end{abstract}

\section{Aim}

To examine the association between older age and diagnostic processes for cancer, and the specific factors that affect diagnosis.

\section{Design and setting}

A systematic literature review.

\section{Method}

Electronic databases were searched for studies of patients aged $>65$ years presenting with cancer symptoms to primary care considering diagnostic decisions. Studies were analysed using thematic synthesis and according to the Synthesis Without Meta-analysis guidelines.

\section{Results}

Data from 54 studies with 230729 participants were included. The majority of studies suggested an association between increasing age and prolonged diagnostic interval or deferral of a decision to investigate cancer symptoms. Thematic synthesis highlighted three important factors that resulted in uncertainty in decisions involving older adults: presence of frailty, comorbidities, and cognitive impairment. Data suggested patients wished to be involved in decision making, but the presence of cognitive impairment and the need for additional time within a consultation were significant barriers.

\section{Conclusion}

This systematic review has highlighted uncertainty in the management of older adults with cancer symptoms. Patients and their family wished to be involved in these decisions. Given the uncertainty regarding optimum management of this group of patients, a shared decision-making approach is important.

\section{Keywords}

cancer; decision making, shared; early detection of cancer; frail elderly; primary health care; systematic review.

\section{INTRODUCTION}

Worldwide the population of those aged $>65$ years is growing faster than any other age group.' The burden of cancer falls predominantly on older patients, with half of all new diagnoses occurring in people aged $>70$ years and incidence rates for all cancers increasing most rapidly in the $>75$ years age group.1,2 The benefits of asymptomatic cancer screening in older adults are unproven and, in most countries, it is not recommended. ${ }^{3,4}$ In countries such as the UK, symptomatic presentation to primary care is the most frequent route to a cancer diagnosis in older adults. ${ }^{5}$

Diagnosing cancer at an early stage is important, and associated with improved survival. ${ }^{6}$ In older adults, these survival benefits are likely to be reduced because of shorter life expectancy. If cancer is diagnosed, older patients who are frail have an increased risk of morbidity and mortality from cancer surgery, and intolerance to chemotherapy and radiotherapy. ${ }^{7}$ As a result, the management of older adults with cancer symptoms in primary care is difficult.8.9 Older adults need a balanced approach to the diagnosis and management of cancer symptoms. The imperative to diagnose cancer early in older adults must

D Jones, PhD, MRCGP, academic clinical lecturer E Di Martino, PhD, research fellow; SH Bradley,

MRCP, clinical research fellow; B Essang, MBChB, academic clinical fellow; S Hemphill MBChB, academic foundation doctor; JM Wright, MSc, FHEA senior information specialist, Leeds Institute of Health Sciences, University of Leeds, Leeds, UK. C Renzi, MD, PhD, principal clinical research fellow, University College London, London, UK. C Surr, BA (Hons), PhD, PGDip, professor of dementia studies and director of the Centre for Dementia Research, Leeds Beckett University, Leeds, UK. A Clegg, BSc, MD, MRCP professor of geriatric medicine and honorary consultant geriatrician, Academic Unit for Ageing \& Stroke Research, University of Leeds, Leeds, UK. N De Wit, MD, PhD, professor of general practice, Julius Center for Health Sciences and be balanced against the prognosis of the cancer, the likely success and tolerance of treatment, the presence of comorbidities, and patient preferences. Some older adults favour quality rather than length of life, ${ }^{10}$ are less likely to want investigation for cancer symptoms, and would accept a higher risk of cancer being undiagnosed. ${ }^{11}$

The aim of this review is to consider the global literature on the association between old age and the diagnostic process for cancer. The objectives were:

- to explore the effect of increasing age on the primary care interval (the time from first presentation to referral) in the diagnosis of cancer;

- to identify the factors that influence the decision to investigate potential cancer symptoms in older adults in primary care, both from a patient and healthcare professional perspective; and

- to understand how the factors identified have an impact on decision making, processes, and outcomes.

\section{METHOD}

\section{Protocol}

Prior to commencing this review, the study protocol was registered with PROSPERO

Primary Care, University Medical Center Utrecht, Utrecht, the Netherlands. R Neal, PhD, FRCGP FHEA, professor of primary care oncology, School of Medicine, University of Leeds, Leeds, UK.

Address for correspondence

Daniel Jones, School of Medicine, University of Leeds, Worsley Building, Leeds LS2 9LU, UK. Email: d.j.jonesवleeds.ac.uk

Submitted: 19 April 2021; Editor's response: 22 June 2021; final acceptance:

27 September 2021.

\section{OThe Authors}

This is the full-length article (published online 16 Nov 2021) of an abridged version published in print. Cite this version as: Br J Gen Pract 2021; DOI: https://doi.org/10.3399/BJGP.2021.0257 


\section{How this fits in}

There is uncertainty in the management of cancer symptoms in primary care. This is the first review, to the authors' knowledge, to consider the effect of older age on decision making by patients and GPs when patients present to primary care with cancer symptoms. Multiple factors were found to influence the patient and GP decision to investigate cancer symptoms including the presence of frailty, comorbidities, and cognitive impairment;

family and carer involvement; and consultation time. Given the uncertainty, a shared decision-making approach is appropriate, but in routine general practice this may be difficult to achieve, mostly because of a lack of time within the consultation.

(reference number: CRD42020180656). The review has been conducted and reported in accordance with the Cochrane Handbook for Systematic Reviews of Interventions ${ }^{12}$ and the PRISMA statement. ${ }^{13}$

\section{Definition of older adults}

There is no universally accepted age threshold for defining old age. The World Health Organization's definition of 'older people' as those aged $\geq 65$ years was adopted in this study. ${ }^{14}$

\section{Eligibility criteria}

Any studies (qualitative and quantitative) of patients aged $\geq 65$ years or with a subgroup of patients aged $\geq 65$ years with symptoms and signs that warrant investigation and referral for suspected cancer presenting to primary care before diagnosis were included. Case-control, cohort, and cross-

\section{Box 1. Systematic review search strategy}

- Applied Social Sciences Index and Abstracts (ASSIA) (ProQuest) 1987 to present

- CINAHL (EBSCOhost) 1981 to present

- Cochrane Central Register of Controlled Trials (Wiley): Issue 4 of 12, April 2020

- Cochrane Database of Systematic Reviews (Wiley): Issue 4 of 12, April 2020

- EMBASE Classic+EMBASE (Ovid) 1947 to 27 April 2020

- Ovid MEDLINE(R) and Epub Ahead of Print, In-Process \& Other Non-Indexed Citations and Daily 1946 to 28 April 2020

- APA PsycINFO (Ovid) 1806 to April Week 32020

- Web of Science Core Collection: Citation Indexes (Clarivate Analytics) 1900 to present

- ISRCTN registry (Springer)

- ClinicalTrials.gov (US National Institutes of Health)

- Evidence Search (National Institute for Health and Care Excellence) sectional studies were included as well as interview and focus group studies. Editorials, single/clinical case studies, reviews, expert opinion articles, and studies that were published as abstracts were excluded from the review.

\section{Search strategy}

On 29 April 2020 electronic databases (Box 1) were searched for published and unpublished studies of cancer-related shared decision making (SDM) for older adults in primary care. See Supplementary Appendix S1 for full search strategies.

Subject headings and free-text words were identified for use in the search concepts by the study authors and based on the search strategy published in a similar review. ${ }^{15}$ No limits (for example, language or date of publication) were applied to the search. The searches were peer reviewed by a second information specialist.

Further relevant studies were sought by searching the citations of included studies, and hand searches of conference abstracts ICancer and Primary Care Research International Network, National Cancer Research Institute, Macmillan Cancer Support, and Cancer Research UK).

\section{Data collection}

All titles and abstracts were independently reviewed by two authors. Any disagreements were resolved through discussion or through adjudication by a third author. Reasons for exclusion were recorded. Data extraction was undertaken using a data extraction template.

\section{Risk of bias of included studies}

The mixed-methods appraisal tool (MMAT) was used to assess the risk of bias for the included studies. ${ }^{16}$ The reviewers' reasons for ratings, including strengths and weaknesses of studies, were recorded independently by two authors before agreeing on a final score.

\section{Synthesis of results}

Meta-analysis was not possible because of the heterogeneity of the included studies. Quantitative studies were therefore analysed using the SWiM (Synthesis Without Meta-analysis) reporting guidelines and checklist. ${ }^{17}$ Qualitative studies were analysed using thematic synthesis described by Thomas and Harden. ${ }^{18}$ Quotes and supporting information were extracted using a template and imported into NVivo (version 12). Quotes and text were then coded line by line before the development of descriptive and analytic themes that 
enabled comparisons and synthesis between studies. This synthesis was undertaken independently by two reviewers. The ENTREQ guidelines were followed for reporting the synthesis of qualitative research. ${ }^{19}$ Following the separate analysis of qualitative and quantitative data, the findings were combined by considering the barriers and facilitators to decision making in primary care. This method was based on previous published guidance on integrating qualitative research in systematic reviews. ${ }^{20}$

\section{RESULTS}

The database searches identified 5336 studies. After title and abstract screening and full-text review, 54 articles were included with 230729 participants
(Figure 1). Studies ranged in size from 9 to 109433 participants. In total, 29 articles included quantitative data, 11,21-48 24 provided qualitative data, ${ }^{49-72}$ and one included both qualitative and quantitative data. ${ }^{48} \mathrm{~A}$ variety of study settings and cancer types were included (see Supplementary Tables S1 and S2). Overall, the quality of studies was judged to be high with an average MMAT across the 54 included studies of 4.6/5.

\section{Quantitative study results}

The 29 quantitative studies included in this review are summarised in Supplementary Table S1. A variety of cancers were investigated in a number of different countries. The association between increasing age and the investigation and referral of cancer symptoms was not related
Identification of studies via databases and registers

\section{Records identified from \\ ASSIA ( $n=99$ )}

CINAHL ( $n=799$ )

Cochrane Central Register

of Controlled Trials ( $n=45$ )

Cochrane Database of

Systematic Reviews ( $n=3$ )

EMBASE $(n=1703)$

MEDLINE $(n=1608)$

PsycINFO ( $n=233$ )

Web of Science Core Collection:

Citation Indexes ( $n=478$ )

ISCRTN ( $n=32$ )

Clinicaltrials.gov $(n=34)$

Evidence Search ( $n=302$ )

Total found in database

search $(n=5336)$

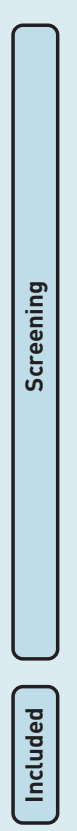

Reports excluded:

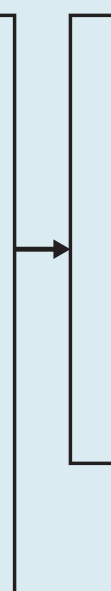

Records removed before

screening:

Duplicate records removed

( $n=1834)$

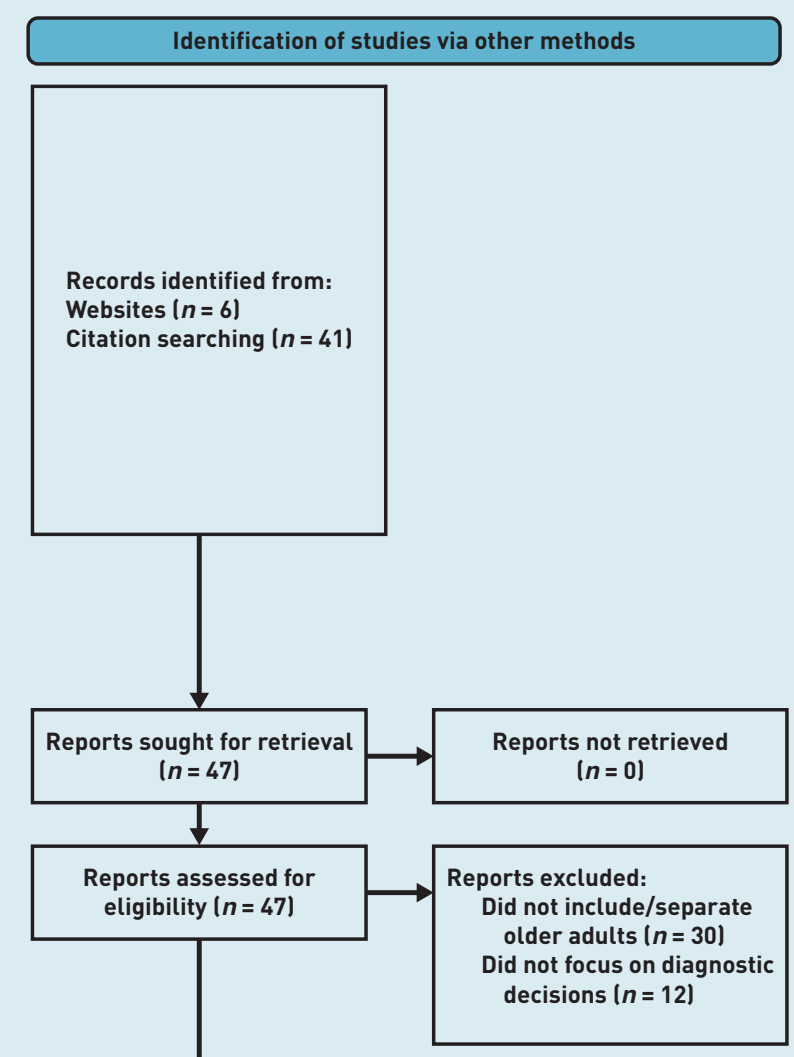

Did not include/separate older adults $(\boldsymbol{n}=95)$

Did not focus on diagnostic

decisions ( $n=28$ )

Did not focus on cancer $(n=24)$

Focus of study was on cancer

screening ( $n=14)$

Study was conducted in

secondary care $(n=11)$

Focus of study was emergency

presentation $(n=3)$ 


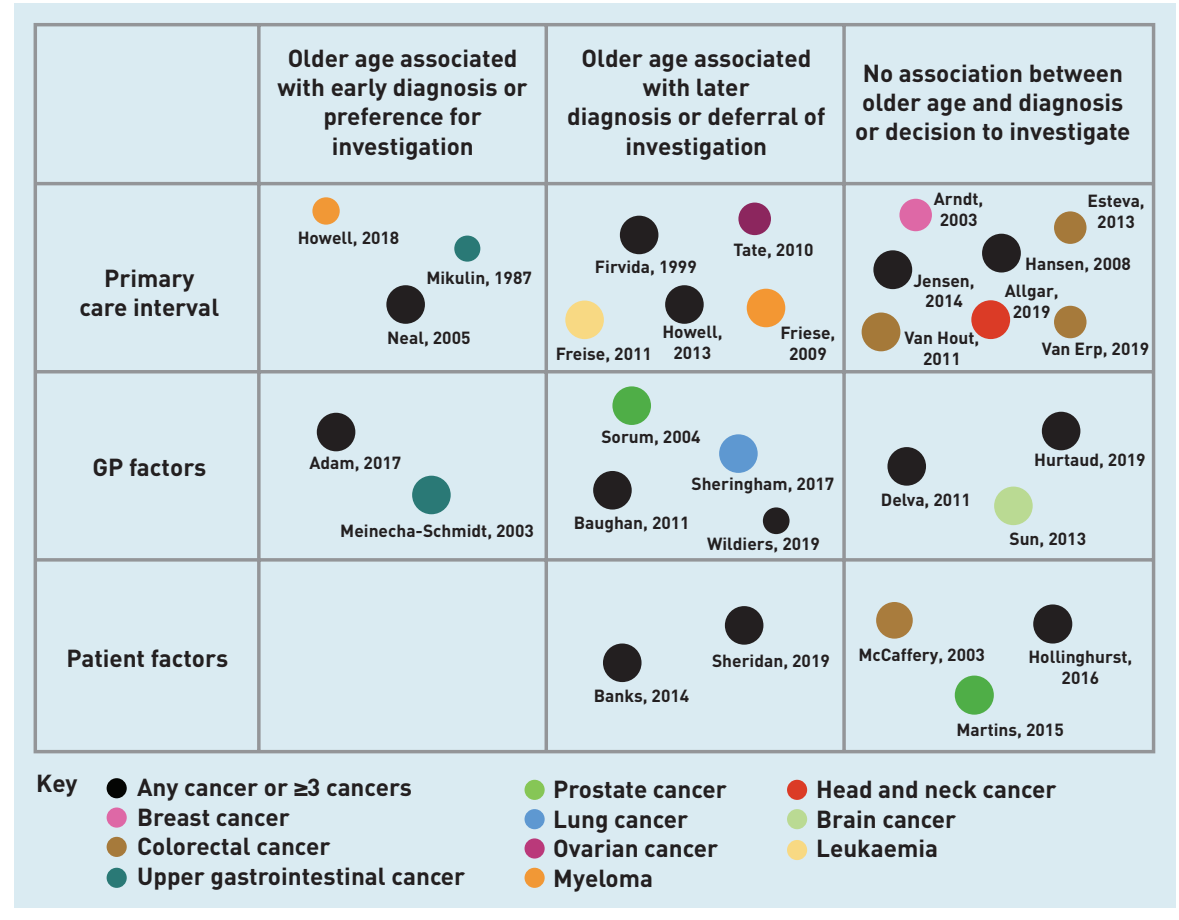

Figure 2. Diagram to show the number of quantitative studies, the association with cancer diagnosis, the cancer investigated, and the quality assessment. Size of circle corresponds to the quality rating judged using MMAT.

MMAT $=$ mixed-methods appraisal tool. to the type of cancer being investigated or the study setting. Outcomes considered by the studies included the association between increasing age and decision making on cancer investigations and referral, and on the primary care interval as defined by the Aarhus Statement. ${ }^{49}$

Fifteen studies considered the length of the primary care interval. Seven studies reported that age was not associated with time to referral or diagnosis, ${ }^{28-34}$ five reported that increasing age was associated with a prolonged diagnostic interval, ${ }^{23-27}$ and three reported increasing age resulted in shorter diagnostic intervals. ${ }^{21,22,48}$

Eleven studies considered the association between increasing age and GP factors that may affect the decision to investigate cancer symptoms. These factors included suspicion of cancer, cancer referral, anticipated regret (because of missed diagnosis), and loss of continuity of care. Two studies found that increasing age was associated with GP factors that would prompt a decision to investigate cancer symptoms. ${ }^{35,36}$ However, five studies suggested that increasing age was associated with factors that would prevent or delay the investigation of cancer symptoms. ${ }^{27,37-40}$ The remaining four studies found that increasing age was not associated with GP factors on decisions to investigate or refer cancer symptoms. 32,41,42,47

Five studies considered the association between increasing age and patient aspects of the diagnostic process. Two studies found that, with increasing age, patient factors such as declining investigations and not attending appointments were more common. ${ }^{11,43}$ Three studies found that age was not associated with patients' preference to proceed with investigations for suspected prostate cancer, patients' wish for cancer investigations, or attitudes towards a cancer diagnosis. .4-46 $^{4}$

These results of the quantitative analysis are summarised in Figure 2. The qualitative results below go some way to explaining these findings.

\section{Qualitative study findings}

Twenty-five studies included in the review provided qualitative data on the association with age and the primary care interval (Supplementary Table S2). ${ }^{48,50-73}$ Thematic synthesis identified the following themes on the decision to investigate or refer cancer symptoms in older adults: the effect of old age on GP and patient decision making; frailty, cognitive impairment, and comorbidities; involving family and carers in decision making; and consultation time. The difficulty of providing adequate time within the primary care consultation for older adults was also highlighted.

The effect of old age on GP and patient decision making. The included studies suggested the presence of significant variation in how GPs and patients managed cancer symptoms in an ageing population. There was evidence that older adults faced additional barriers to diagnosis, with cancer symptoms sometimes being attributed to the 'effects of old age' by both patients and GPs. Data suggested that GPs could make decisions on behalf of patients but this may result in depersonalisation and a loss of autonomy. One study suggested that GPs may apply their own personal values to decision making, which could be at odds with that of the patient. .9 In $^{9}$ contrast, there was also evidence of doctors considering quality of life and life expectancy when making decisions rather than age alone, which affected the likelihood of investigation and referral. These findings are summarised in Box 2.

Frailty, cognitive impairment, and comorbidities. Frailty, comorbidities, and cognitive impairment were highlighted as important themes throughout the qualitative synthesis, and are summarised in Box 3. The study analysis suggested that GPs undertook an assessment of a patient's overall health or frailty when making decisions about the investigation or referral for cancer symptoms. Older adults deemed 


\section{Box 2. Themes and illustrative quotes demonstrating the effect of old age on GP and patient decision making}

\begin{tabular}{ll} 
Theme & Subtheme \\
\hline $\begin{array}{l}\text { Old age alone can } \\
\text { affect decision }\end{array}$ & $\begin{array}{l}\text { Possible cancer symptoms } \\
\text { are attributed to the ageing } \\
\text { making }\end{array}$ \\
process
\end{tabular}

Healthcare professionals may make decisions on behalf of older patients

Healthcare professionals' personal values may be at odds with those of the patient and carers

Old age alone should not delay investigation and referral

\section{Illustrative quotes}

A GP stated:

I find that there can be a short delay in

management, because we tend to trivialise symptoms that can be attributed to age, fatigue, asthenia, maybe a slight anaemia, things that are relatively trivial. We tend to say it's just age. ${ }^{56}$

A patient stated:

It was ... a gradual process, which I put down to old age ... [and] I'd had a bad back, so I was quite sort of willing to accept that my back hurts a bit. ${ }^{48}$

With an elderly patient, certain specialists and general practitioners have a tendency to make the decision on behalf of the patient, which is an important problem. ${ }^{56}$

The carer recalled that the GP stated:

for what life shall we save him?

The carer further reported:

it was like he didn't want anything to be done, that there was no point in doing anything, and that we should be satisfied with taking the world as we found it." ${ }^{69}$

A GP stated:

I have folks [in whom] we're doing certain tests and things well beyond what generally is recommended but I think for good reason ... I have a couple patients in their late 80s and 90s where I tell them: "you're likely to live another decade or two ... so we might need to be a little more aggressive ... ". 71

to be frail or in poor health were less likely to be investigated or referred if they developed cancer symptoms. However, the evidence base behind these assessments of frailty were questioned by patients and GPs. There was a concern that GPs could overestimate frailty, especially with older adults in care homes, which could negatively affect the investigation and referral for cancer symptoms in these patients.

The presence of cognitive impairment had a similar effect to that of frailty in the study analysis. Some GPs were less likely to investigate patients with dementia because of the perception that patients with cognitive impairment may be distressed by medical examinations or investigations and not benefit from a diagnosis of cancer. However, it was also recognised that patients with cognitive impairment may be physically fit and have a good quality of life, and as a result that it was necessary to "continue to fight', as one GP put it. ${ }^{56}$ The presence of cognitive impairment was also identified as a barrier to SDM.

The study analysis suggest that comorbidities such as osteoarthritis,

chronic back pain, chronic obstructive pulmonary disease, cerebrovascular disease, and anxiety and depression were attributed as a cause for symptoms by both GPs and patients. This frequently resulted in a delay in the investigation or referral for cancer symptoms. However, there were also examples of cancer symptoms being investigated as a result of attending routine health checks for comorbidities.

Involving family and carers in decision making. As a result of advanced age, frailty, or cognitive impairment, there were frequent discussions about the impact of a patient's family or carers on the decisions made in primary care, especially in patients with cognitive impairment (Box 4).

The studies suggested that, if patients had advanced cognitive impairment, then that patient's family and carers should be involved in decisions on investigation of cancer symptoms. However, there was concern that the wishes of the family and carers may not support those of the patient. There were also concern over the level of responsibility that should be managed by relatives.

Consultation time. It was recognised by both patients and GPs that time constraints within the consultation could limit the communication of symptoms by patients. Although a lack of time in the consultation could affect patients of all ages, it was more likely to affect older adults because of the presence of frailty, comorbidities, and cognitive impairment, resulting in more complex consultations.

A study of GPs found that most were aware that time constraints within consultations with older adults limited what could be discussed. ${ }^{60}$ Two studies highlighted problems with policies such as 'one appointment, one problem', which may not suit an older patient demographic. ${ }^{74,75}$ However, there was evidence that GPs considered the practicalities of older adults attending appointments, with one GP suggesting that older adults may find afternoon appointments easier. ${ }^{60}$

\section{DISCUSSION}

\section{Summary}

To the authors knowledge, this is the first systematic review to explore the effect of old age on the investigation and referral of cancer in primary care. The majority of studies suggest a possible association between increased age and a prolonged diagnostic interval or deferred cancer investigations. The findings suggest that, for 


\begin{tabular}{|c|c|c|}
\hline Theme & Subtheme & Illustrative quotes \\
\hline \multirow[t]{3}{*}{ Frailty } & $\begin{array}{l}\text { Healthcare professionals are informally assessing } \\
\text { frailty }\end{array}$ & $\begin{array}{l}\text { A GP stated: } \\
\text { I've never used any specific scale to assess anyone's frailty. I don't know what the evidence is } \\
\text { behind that frailty score. }{ }^{50}\end{array}$ \\
\hline & $\begin{array}{l}\text { Healthcare professionals are less likely to } \\
\text { investigate or refer patients they deem to be frail }\end{array}$ & $\begin{array}{l}\text { A GP stated: } \\
\text { 'We need to consider ... the psychological and organic weaknesses that mean, possibly } \\
\text { justifiably, that we shouldn't do as much as we would with a younger person. '56 } \\
\text { A GP stated: } \\
\text { 'This woman in her } 80 \text { s had a breast mass ... she [had] poor life expectancy, she was already on } \\
\text { home oxygen, heart failure, all those comorbid conditions, we could see her lungs failing, and } \\
\text { I don't think we need to do anything about [the breast mass]. }{ }^{71}\end{array}$ \\
\hline & Assumptions about frailty may prevent investigation & $\begin{array}{l}\text { A GP stated: } \\
\text { 'There may be a degree [of] assumption going on "I don't think Mrs Bloggs is well enough" and } \\
\text { I wonder whether there is a better way... }{ }^{50}\end{array}$ \\
\hline \multirow[t]{4}{*}{$\begin{array}{l}\text { Cognitive } \\
\text { impairment }\end{array}$} & $\begin{array}{l}\text { Healthcare professionals are less likely to } \\
\text { investigate or refer older patients they deem to be } \\
\text { cognitively impaired }\end{array}$ & $\begin{array}{l}\text { A GP stated: } \\
\text { Well, I don't push the investigation or anything ... For me, it's really a complete hindrance to } \\
\text { send people for investigations to seek out cancerous pathology. }{ }^{56}\end{array}$ \\
\hline & $\begin{array}{l}\text { Older patients with cognitive impairment may be } \\
\text { distressed by examinations or investigations }\end{array}$ & $\begin{array}{l}\text { An older patient with dementia who had undergone tests for colorectal cancer stated: } \\
\text { 'That woman who ran around and hurt me. Well, she didn't know what she were doing. } \\
\text { "No!" I kept saying to her. I said "It's not right!" Two people hit at me.' } \\
\text { The study reported that there were also signs of distress during the interview, 'contorting her } \\
\text { face' and 'wringing her hands with worry', which showed the pain and distress of undergoing } \\
\text { intimate clinical investigations. }\end{array}$ \\
\hline & $\begin{array}{l}\text { The presence of cognitive impairment can affect } \\
\text { communication with healthcare professionals }\end{array}$ & $\begin{array}{l}\text { A 79-year-old with colorectal cancer stated it was his wife who had noticed the patient's } \\
\text { symptoms: } \\
\text { I have Alzheimer's disease and my wife noticed the change in bowel habits. I had no other signs } \\
\text { or symptoms. }{ }^{67}\end{array}$ \\
\hline & $\begin{array}{l}\text { Despite cognitive impairment, patients may be fit } \\
\text { and investigation could be warranted }\end{array}$ & $\begin{array}{l}\text { A GP stated: } \\
\text { Even if they're very cognitively impaired, we can still share plenty of things, and often they find } \\
\text { that it's worthwhile to continue to fight.' }{ }^{.56}\end{array}$ \\
\hline \multirow[t]{2}{*}{ Comorbidities } & $\begin{array}{l}\text { Investigation and referral of symptoms possibly } \\
\text { owing to cancer were delayed because of } \\
\text { comorbidities }\end{array}$ & $\begin{array}{l}\text { The carer of a 78-year-old man recalled how the GP attributed his signs of illness to pain from a } \\
\text { knee replacement: } \\
\text { 'We said, you know, he's really finding it hard to mobilise and you know, loss of appetite and } \\
\text { depression. And, [the GP] instead of looking for another reason, it was, "oh well, he's in pain. } \\
\text { You know, if you sort the pain out, we'll sort the other bits out". "55 } \\
\text { A } 72 \text {-year-old woman with ovarian cancer and longstanding back pain reported: } \\
\text { 'I first visited my doctor about my symptoms... I was not examined. I was told the pain was } \\
\text { coming from my back (I had a back problem for years]. ".7 } \\
\text { I've got COPD [chronic obstructive pulmonary disease] but I never coughed up blood before. I } \\
\text { thought it will clear up but after two weeks it didn't so I thought I had better get it checked. } 53\end{array}$ \\
\hline & $\begin{array}{l}\text { Annual check-ups for comorbidities resulted } \\
\text { in opportunities for earlier diagnosis }\end{array}$ & $\begin{array}{l}\text { 'The cancer was only found on annual chest check for COPD. }{ }^{67} \\
\text { A patient laged between } 85 \text { and } 89 \text { years) with lung cancer stated: } \\
\text { I go six monthly to the nurse in the clinic and / mentioned to her / was spitting blood and she } \\
\text { said "well make an appointment with the doctor"... "53 }\end{array}$ \\
\hline
\end{tabular}

patients and GPs, deciding how to manage older patients with symptoms that could herald a cancer diagnosis is challenging. As well as an assessment of the patient's wishes, such decisions often require an assessment of patients' overall health or frailty, along with a judgement as to whether the harms of investigation or referral would be justified by benefits.

There is significant variation in the findings of the studies included in this review. Some studies found that older adults and those with high levels of frailty or comorbidity had prolonged diagnostic intervals or were not investigated for possible cancer, which were in direct contrast with other studies in the same patient group. This variation may reflect uncertainty and a lack of evidence regarding the management of cancer symptoms in older adults. Judgements undertaken by GPs based on a patient's age or perceived frailty could result in inconsistency and a high degree of variation in clinical practice. However, the variation 


\section{Box 4. Themes and illustrative quotes demonstrating the impact of a patient's family or carers on the decisions made in primary care}

\begin{tabular}{|c|c|c|}
\hline Theme & Subtheme & Illustrative quotes \\
\hline \multirow[t]{3}{*}{ Family and carers } & $\begin{array}{l}\text { Family and carers should be } \\
\text { involved in decision making } \\
\text { in patients with cognitive } \\
\text { impairment }\end{array}$ & $\begin{array}{l}\text { A GP stated: } \\
\text { 'If we're referring to patients with advanced cognitive } \\
\text { impairment ... it's obvious that the decision should be } \\
\text { taken with the carers, those close to the patient, their } \\
\text { family... }{ }^{56}\end{array}$ \\
\hline & $\begin{array}{l}\text { The wishes of family and } \\
\text { carers may be at odds with } \\
\text { the wishes of the patient }\end{array}$ & $\begin{array}{l}\text { A GP stated: } \\
\text { A } 50 \text {-year-old who says to you "If I'm ever in that } \\
\text { position, let me go, don't insist, let me die or help me } \\
\text { to die", but when they [the family] face that situation } \\
\text { [later in life], if the smallest door of hope opens, they } \\
\text { [the family] take it; it's normal." }{ }^{6} 6\end{array}$ \\
\hline & $\begin{array}{l}\text { What level of responsibility } \\
\text { should be taken by the } \\
\text { family or carers? }\end{array}$ & $\begin{array}{l}\text { Uncertainty extended to knowing how much, or how } \\
\text { little, they [the family] were to be involved in the } \\
\text { clinical investigations consent process of their relative } \\
\text { with dementia and what level of responsibility - if any } \\
\text { - they shouldered in taking such a decision. }{ }^{63}\end{array}$ \\
\hline
\end{tabular}

could also be the result of well-balanced decisions to postpone investigations because of a low likelihood of benefit from a cancer diagnosis and a higher risk of complications from cancer investigations or treatment. Finally, it may be a consequence of patient preference in shared decisions around investigation.

The review has highlighted both patients and their families' wishes to be involved in decisions around care. Given the uncertainty regarding optimum management of this group of patients, an SDM approach is likely to be helpful. However, it is not clear how best to implement this, and several barriers to its use were highlighted in this review, most notably the presence of cognitive impairment and the need for additional time within a consultation to fully inform the patient and allow for SDM.

\section{Strengths and limitations}

This large systematic review of 54 studies has been robustly carried out and demonstrates important and novel findings for patients and primary care practitioners. Studies were included from a variety of countries and investigated a wide range of cancer types. The heterogeneity of included studies precluded meta-analysis and may have also resulted in contrasting findings. There is inconsistency in the use of terms to describe the primary care interval within the literature and included studies. This was addressed in the current study by reviewing the details of each study against the inclusion criteria. The MMAT for quality assessment was chosen as both qualitative and quantitative studies were included; however, the tool was found to be limited in discriminating study quality. Finally, many of the included studies, particularly the qualitative ones, included few participants and as a result may not be generalisable to the older adult population as a whole.

\section{Comparison with existing literature}

Although this is the first review, to the authors' knowledge, to consider the effect of age on diagnostic decisions, there are multiple studies concerning the treatment decisions of older adults who are frail and have a diagnosis of cancer. These studies are largely based in secondary care and have other competing factors to consider, such as the side effects of potential treatments and the chances of success. However, the effect of age, frailty, comorbidities, and cognitive impairment are frequently highlighted in these studies. Overall, the results of this review are supported by the findings of work undertaken on cancer treatment.

A systematic review on the effect of frailty on cancer outcomes found that patients with cancer and a diagnosis of frailty had increased all-cause mortality, increased postoperative mortality, and more frequent complications of treatment than patients with cancer without a diagnosis of frailty. A review on the impact of comorbidity on cancer treatment found similar results. The review reports that patients with comorbidity had poorer survival, poorer quality of life, and higher healthcare costs than those without comorbidities. ${ }^{76}$ A systematic review on the effect of dementia on cancer outcomes found that patients with dementia and cancer had a reduced likelihood of receiving: cancer screening, cancer staging information, cancer treatment with curative intent, and pain management compared with those with cancer only. ${ }^{77}$ A qualitative study on the information needs of patients with dementia making decisions about cancer treatment found that cancer treatment was adjusted because of dementia; that there were difficulties in communicating clinical information that resulted in the frequent involvement of informal caregivers; and a need for information on the functional impact of dementia and how this will affect cancer treatment. ${ }^{78}$ These studies are largely based in secondary care and have other competing factors to consider, such as the side effects of potential treatments and the chances of success. However, the effect of age, frailty, comorbidities, and cognitive impairment are frequently highlighted in these studies. Overall, the results of this 
review are supported by the findings of work undertaken on cancer treatment.

\section{Implications for research and practice}

National guidelines on investigation and referral of patients with cancer symptoms do not consider older age or frailty. ${ }^{1,79}$ However, the question of whether healthcare professionals should treat older adults with cancer symptoms differently remains. ${ }^{9}$ It is not possible to make appropriate management decisions on the basis of age alone, as many patients remain active and healthy well into advanced age, or may express preferences about investigation and treatment. Even patients who may not be able to tolerate aggressive cancer treatments might still benefit from diagnosis, for example, should they wish to know about prognosis or to access palliative care. This review highlights uncertainty in both patients' and GPs' views and decisions surrounding the investigation and referral of older adults with cancer symptoms. In this context of uncertainty, an SDM approach is most appropriate.? This would allow patients, and in some cases their family, to evaluate the pros and cons of diagnostic referral on an individual basis. SDM is a key part of the NHS Long Term Plan, ${ }^{80}$ which advocates personalised care across the whole care system.

Barriers to the use of SDM, however, were apparent in the review. The authors of this current study consider in a primary care consultation that there is insufficient time to fully undertake SDM, with the presence of cognitive impairment, comorbidities, and frailty; complex medical/social circumstances; the need for assessments of capacity; and to involve family members. Significant work has been undertaken to understand the use of SDM and holistic geriatric assessment tools to aid decision making for cancer treatment. ${ }^{81}$ These barriers might be addressed by further use of pre-diagnostic frailty scoring systems and holistic assessments of older adults, and may benefit from further development of geriatric oncology services expanding into primary care, as has been suggested in work considering frailty and cancer treatment?

\section{Funding}

This research is linked to the CanTest Collaborative, which is funded by Cancer Research UK (reference: C8640/A23385), of which Richard Neal and Niek De Wit are associate directors and Erica Di Martino, Stephen H Bradley, and Cristina Renzi are research fellows.

\section{Ethical approval}

Not applicable.

\section{Data}

The full search strategy and all data are available in the supplementary material.

\section{Provenance}

Freely submitted; externally peer reviewed.

\section{Competing interests}

The authors have declared no competing interests.

\section{Open access}

This article is Open Access: CC BY 4.0 licence (http://creativecommons.org/ licences/by/4.0/).

\section{Discuss this article}

Contribute and read comments about this article: bjgp.org/letters 


\section{REFERENCES}

1. GBD 2019 Diseases and Injuries Collaborators. Global burden of 369 diseases and injuries in 204 countries and territories, 1990-2019: a systematic analysis for the Global Burden of Disease Study 2019. Lancet 2020; 396(10258): 12041222

2. Cancer Research UK. Cancer statistics for the UK. https://www. cancerresearchuk.org/health-professional/cancer-statistics-for-the-uk laccessed 22 Oct 2021).

3. NHS Digital. NHS screening. 2021. https://www.nhs.uk/conditions/nhsscreening laccessed 22 Oct 2021).

4. Royce TJ, Hendrix LH, Stokes WA, et al. Cancer screening rates in individuals with different life expectancies. JAMA Intern Med 2014; 174(10): 1558-1565.

5. Din NU, Ukoumunne OC, Rubin G, et al. Age and gender variations in cancer diagnostic intervals in 15 cancers: analysis of Data from the UK Clinical Practice Research Datalink. PLoS One 2015; 10(5): e0127717.

6. Neal RD, Tharmanathan P, France B, et al. Is increased time to diagnosis and treatment in symptomatic cancer associated with poorer outcomes? Systematic review. Br J Cancer 2015; 112 Suppl 1(Suppl 1): S92-S107.

7. Handforth C, Clegg A, Young C, et al. The prevalence and outcomes of frailty in older cancer patients: a systematic review. Ann Oncol 2015; 26(6): 1091-1101.

8. van de Pol MHJ, Fluit CRMG, Lagro J, et al. Shared decision making with frail older patients: proposed teaching framework and practice recommendations. Gerontol Geriatr Educ 2016; 38(4): 482-495.

9. Jones D, di Martino E, Hatton NL, et al. Investigating cancer symptoms in older people: what are the issues and where is the evidence? Br J Gen Pract 2020; DOI: https://doi.org/10.3399/bjgp20X710789

10. Shrestha A, Martin C, Burton M, et al. Quality of life versus length of life considerations in cancer patients: a systematic literature review. Psycho-Oncol 2019; 28(7): 1367-1380

11. Banks J, Hollinghurst S, Bigwood L, et al, Preferences for cancer investigation: a vignette-based study of primary-care attendees. Lancet Oncol 2014; 15(2): 232-240.

12. Higgins JPT, Thomas J, Chandler J, et al. eds. Cochrane handbook for systematic reviews of interventions. Hoboken, NJ: John Wiley \& Sons, 2019

13. Moher D, Liberati A, Tetzlaff J, et al. Preferred reporting items for systematic reviews and meta-analyses: the PRISMA statement. BMJ 2009; 339(1): b2535.

14. World Health Organization. Proposed working definition of an older person in Africa for the MDS project. Geneva: WHO, 2002.

15. Puts MT, Tapscott B, Fitch M, et al. A systematic review of factors influencing older adults' decision to accept or decline cancer treatment. Cancer Treat Rev 2015; 41(2): 197-215.

16. Hong QN, Gonzalez-Reyes A, Pluye P. Improving the usefulness of a tool for appraising the quality of qualitative, quantitative and mixed methods studies, the Mixed Methods Appraisal Tool (MMAT). J Eval Clin Pract 2018; 24(3): 459-467.

17. Campbell M, McKenzie JE, Sowden A, et al. Synthesis without meta-analysis (SWiM) in systematic reviews: reporting guideline. BMJ 2020; 368: 16890.

18. Thomas J, Harden A. Methods for the thematic synthesis of qualitative research in systematic reviews. BMC Med Res Methodol 2008; 8: 45.

19. Tong A, Flemming K, Mclnnes E, et al. Enhancing transparency in reporting the synthesis of qualitative research: ENTREQ. BMC Med Res Methodol 2012; 12: 181.

20. Thomas J, Harden A, Oakley A, et al. Integrating qualitative research with trials in systematic reviews. BMJ 2004; 328(7446): 1010-1012.

21. Neal RD, Allgar VL. Sociodemographic factors and delays in the diagnosis of six cancers: analysis of data from the "National Survey of NHS Patients: Cancer". Br J Cancer 2005; 92(11): 1971-1975

22. Mikulin T, Hardcastle JD. Gastric cancer - delay in diagnosis and its causes. Eur J Cancer Clin Oncol 1987; 23(11): 1683-1690.

23. Firvida JL, Vinolas N, Munoz M, et al. Age: a critical factor in cancer management. A prospective comparative study of 400 patients. Age Ageing 1999; 28(2): 103-105

24. Friese CR, Abel GA, Magazu LS, et al. Diagnostic delay and complications for older adults with multiple myeloma. Leuk Lymphoma 2009; 50(3): 392-400.

25. Friese CR, Earle CC, Magazu LS, et al. Timeliness and quality of diagnostic care for Medicare recipients with chronic lymphocytic leukemia. Cancer 2011; 117(7): 1470-1477
26. Howell DA, Smith AG, Jack A, et al. Time-to-diagnosis and symptoms of myeloma, lymphomas and leukaemias: a report from the Haematological Malignancy Research Network. BMC Hematology 2013; 13(1): 9

27. Tate AR, Nicholson A, Cassell JA. Are GPs under-investigating older patients presenting with symptoms of ovarian cancer? Observational study using General Practice Research Database. Br J Cancer 2010; 102(6): 947-951.

28. Allgar VL, Oliver SE, Chen H, et al. Time intervals from first symptom to diagnosis for head and neck cancers: an analysis of linked patient reports and medical records from the UK. Cancer Epidemiol 2019; 59: 37-45.

29. Arndt V, Sturmer T, Stegmaier C, et al. Provider delay among patients with breast cancer in Germany: a population-based study. J Clin Oncol 2003; 21(8): 1440-1446.

30. Esteva M, Leiva A, Ramos M, et al. Factors related with symptom duration until diagnosis and treatment of symptomatic colorectal cancer. BMC Cancer 2013; 13: 87.

31. Hansen RP, Olesen F, Sørensen HT, et al. Socioeconomic patient characteristics predict delay in cancer diagnosis: a Danish cohort study. BMC Health Serv Res 2008; 8: 49

32. Jensen $\mathrm{H}$, Torring ML, Olesen $\mathrm{F}$, et al. Cancer suspicion in general practice, urgent referral and time to diagnosis: a population-based GP survey and registry study. BMC Cancer 2014; 14: 636

33. van Erp NF, Helsper CW, Olyhoek SM, et al. Potential for reducing time to referral for colorectal cancer patients in primary care. Ann Fam Med 2019; 17(5): 419-427.

34. Van Hout AM, de Wit NJ, Rutten FH, et al. Determinants of patient's and doctor's delay in diagnosis and treatment of colorectal cancer. Eur J Gastroenterol Hepatol 2011; 23(11): 1056-1063.

35. Adam R, Garau R, Raja EA, et al. Do patients' faces influence General Practitioners' cancer suspicions? A test of automatic processing of sociodemographic information. PLoS One 2017; 12(11): e0188222.

36. Meineche-Schmidt V, Jorgensen T. 'Alarm symptoms' in dyspepsia: how does the general practitioner investigate? Scan J Prim Health Care 2003; 21(4): 224-229.

37. Baughan P, Keatings J, O'Neill B. Urgent suspected cancer referrals from general practice: audit of compliance with guidelines and referral outcomes. $\mathrm{Br}$ J Gen Pract 2011; DOI: https://doi.org/10.3399/bjgp11X606591.

38. Sheringham J, Sequeira R, Myles J, et al. Variations in GPs' decisions to investigate suspected lung cancer: a factorial experiment using multimedia vignettes. BMJ Qual Saf 2017; 26(6): 449-459.

39. Sorum PC, Mullet E, Shim J, et al. Avoidance of anticipated regret: the ordering of prostate-specific antigen tests. Med Decis Making 2004; 24(2): 149-159.

40. Wildiers H, Mauer M, Elseviers M, et al. Cancer events in Belgian nursing home residents: an EORTC prospective cohort study. J Geriatr Oncol 2019; 10(5): 805-810.

41. Delva F, Marien E, Fonck M, et al. Factors influencing general practitioners in the referral of elderly cancer patients. BMC Cancer 2011; 11: 5.

42. Sun $\mathrm{Z}, \mathrm{Ng} \mathrm{C}$, Halkett $\mathrm{G}$, et al. An investigation of factors that influence general practitioners' referral of computed tomography scans in patients with headache. Int J Clin Pract 2013; 67(7): 682-690.

43. Sheridan R, Oliver SE, Hall G, et al. Patient non-attendance at urgent referral appointments for suspected cancer and its links to cancer diagnosis and one year mortality: a cohort study of patients referred on the two week wait pathway. Cancer Epidemiol 2019; 63: 101588.

44. McCaffery K, Wardle J, Waller J. Knowledge, attitudes, and behavioral intentions in relation to the early detection of colorectal cancer in the United Kingdom. Prev Med 2003; 36(5): 525-535

45. Martins T, Ukoumunne OC, Banks J, et al. Ethnic differences in patients' preferences for prostate cancer investigation: a vignette-based survey in primary care. Br J Gen Pract 2015; DOI: http://doi.org/10.3399/bjgp15X683965.

46. Hollinghurst $\mathrm{S}$, Banks J, Bigwood L, et al. Using willingness-to-pay to establish patient preferences for cancer testing in primary care. BMC Med Inform Decis Mak 2016; 16: 105

47. Hurtaud A, Aubin M, Ferrat E, et al. Continuity of care in general practice at cancer diagnosis (COOC-GP study): a national cohort study of 2853 patients. $\mathrm{Br}$ J Gen Pract 2019; DOI: http://doi.org/10.3399/bjgp19X700805.

48. Howell DA, Hart RI, Smith AG, et al. Myeloma: patient accounts of their pathways to diagnosis. PLoS One 2018; 13(4): e0194788. 
49. Weller D, Vedsted P, Rubin G, et al. The Aarhus statement: improving design and reporting of studies on early cancer diagnosis. Br J Cancer 2012; 106(7): 1262-1270

50. Allen K, Brown H, Singh K, et al. Advancing care, advancing years: improving cancer treatment and care for an ageing population. London: Cancer Research UK, 2018.

51. Andersen RS, Paarup B, Vedsted P, et al. 'Containment' as an analytical framework for understanding patient delay: a qualitative study of cancer patients' symptom interpretation processes. Soc Sci Med 2010; 71(2): 378-385.

52. Bain NS, Campbell NC, Ritchie LD, et al. Striking the right balance in colorectal cancer care - a qualitative study of rural and urban patients. Fam Pract 2002; 19(4): 369-374.

53. Birt L, Hall N, Emery J, et al. Responding to symptoms suggestive of lung cancer: a qualitative interview study. BMJ Open Respir Res 2014; 1(1): e000067.

54. Broughton M, Bailey J, Linney J. How can experiences of patients and carers influence the clinical care of large bowel cancer? Eur J Cancer Care 2004; 13(4): 318-327.

55. Caswell G, Seymour J, Crosby V, et al. Lung cancer diagnosed following an emergency admission: exploring patient and carer perspectives on delay in seeking help. Support Care Cancer 2017; 25(7): 2259-2266.

56. Chicoulaa B, Balardy L, Stillmunkes A, et al. French general practitioners' sense of isolation in the management of elderly cancer patients. Fam Pract 2016; 33(5): 551-556.

57. Evans J, Ziebland S, McPherson A. Minimizing delays in ovarian cancer diagnosis: an expansion of Andersen's model of 'total patient delay'. J Fam Pract 2007; 24(1): 48-55

58. Evans REC, Morris M, Sekhon M, et al. Increasing awareness of gynaecological cancer symptoms: a GP perspective. Br J Gen Pract 2014; DOI: https://doi. org/10.3399/bjgp14X680161.

59. Issah F, Maree JE, Mwinituo PP. Expressions of cervical cancer-related signs and symptoms. Eur J Oncol Nurs 2011; 15(1): 67-72.

60. Jefferson L, Atkin K, Sheridan R, et al. Non-attendance at urgent referral appointments for suspected cancer: a qualitative study to gain understanding from patients and GPs. Br J Gen Pract 2019; DOI: https://doi.org/10.3399/ bjgp19X706625

61. King-Okoye M, Arber A, Faithfull S. Beliefs that contribute to delays in diagnosis of prostate cancer among Afro-Caribbean men in Trinidad and Tobago. Psycho Oncol 2019; 28(6): 1321-1327.

62. Leydon GM, Bynoe-Sutherland J, Coleman MP. The journey towards a cancer diagnosis: the experiences of people with cancer, their family and carers. Eur $J$ Cancer Care 2003; 12(4): 317-326.

63. McWilliams L, Swarbrick C, Yorke J, et al. Bridging the divide: the adjustment and decision-making experiences of people with dementia living with a recent diagnosis of cancer and its impact on family carers. Ageing Soc 2018; $\mathbf{4 0 ( 5 ) : ~}$ 944-965.

64. Mitchell ED, Rubin G, Macleod U. Understanding diagnosis of lung cancer in primary care: qualitative synthesis of significant event audit reports. $\mathrm{Br} J \mathrm{Gen}$ Pract 2013; 63(606): e37-e46

65. Neal RD, Robbe IJ, Lewis M, et al. The complexity and difficulty of diagnosing lung cancer: findings from a national primary-care study in Wales. Prim Health Care Res Dev 2015; 16(5): 436-449.
66. Oberoi DV, Jiwa M, McManus A, et al. Help-seeking experiences of men diagnosed with colorectal cancer: a qualitative study. Eur J Cancer Care 2016. 25(1): 27-37.

67. Parsonage RK, Hiscock J, Law RJ, Neal RD. Patient perspectives on delays in diagnosis and treatment of cancer: a qualitative analysis of free-text data. $\mathrm{Br} J$ Gen Pract 2017; DOI: https://doi.org/10.3399/bjgp16X688357.

68. Rankin NM, York S, Stone E, et al. Pathways to lung cancer diagnosis: a qualitative study of patients and general practitioners about diagnostic and pretreatment intervals. Ann Am Thorac Soc 2017; 14(5): 742-753.

69. Salander $\mathrm{P}$, Bergenheim AT, Hamberg K, et al. Pathways from symptoms to medical care: a descriptive study of symptom development and obstacles to early diagnosis in brain tumour patients. Fam Pract 1999; 16(2): 143-148.

70. Samuelsson KS, Egenvall M, Klarin I, et al. The older patient's experience of the healthcare chain and information when undergoing colorectal cancer surgery according to the enhanced recovery after surgery concept. J Clin Nurs 2018; 27(7-8): e1580-e1588.

71. Schoenborn NL, Bowman TL, Cayea D, et al. Primary care practitioners' views on incorporating long-term prognosis in the care of older adults. JAMA Int Med 2016; 176(5): 671-678

72. Topping A, Nkosana-Nyawata I, Heyman B. 'I am not someone who gets skin cancer': risk, time and malignant melanoma. Health Risk Soc 2013; 15(6): $596-614$

73. van Schalkwyk SL, Maree JE, Wright SC. Cervical cancer: the route from signs and symptoms to treatment in South Africa. J Reprod Health Matters 2008 16(32): 9-17.

74. McCutchan G, Wood F, Smits S, et al. Barriers to cancer symptom presentation among people from low socioeconomic groups: a qualitative study. BMC Public Health 2016; 16(1): 1052

75. Tookey S, Renzi C, Waller J, et al. Using the candidacy framework to understand how doctor-patient interactions influence perceived eligibility to seek help for cancer alarm symptoms: a qualitative interview study. BMC Health Serv Res 2018; 18(1): 937

76. Sarfati D, Koczwara B, Jackson C. The impact of comorbidity on cancer and its treatment. CA Cancer J Clin 2016; 66(4): 337-350.

77. McWilliams L, Farrell C, Grande G, et al. A systematic review of the prevalence of comorbid cancer and dementia and its implications for cancer-related care. Aging Mental Health 2017; 22(10): 1254-1271

78. McWilliams L, Farrell C, Keady J, et al. Cancer-related information needs and treatment decision-making experiences of people with dementia in England: a multiple perspective qualitative study. BMJ Open 2018; 8(4): e020250.

79. National Institute for Health and Care Excellence. Suspected cancer: recognition and referral. NG12. London: NICE, 2021 https://www.nice.org.uk/ guidance/ng12 (accessed 4 Nov 2021).

80. NHS England. The NHS Long Term Plan. 2019. https://uww.longtermplan.nhs. uk/publication/nhs-long-term-plan laccessed 22 Oct 2021).

81. Soto-Perez-de-Celis E, Li D, Yuan Y, et al. Functional versus chronological age geriatric assessments to guide decision making in older patients with cancer. Lancet Oncol 2018; 19(6): e305-e316. 